\title{
POR QUE AINDA LEMOS REVISTAS DE POESIA? APONTAMENTOS PARA O ESTUDO DA POESIA BRASILEIRA EM SUAS REVISTAS
}

\author{
Maria Lucia de Barros Camargo \\ UFSC / CNPq
}

Resumo

Este trabalho apresenta como objeto de leitura $e$ análise um conjunto de revistas de poesia que circularam ou ainda circulam no Brasil, na forma impressa, a partir da última década do século XX, tendo poetas como seus editores. Prática coletiva e/ou revistas de um homem só? Singulares e/ou plurais? Existências encerradas em si mesmas e/ ou partícipes de uma rede compartilhada de experiências, objetos e objetivos poéticos? A proposta é analisar a hipótese de que as revistas literárias podem ser consideradas como uma condição de possibilidade para a política da literatura (Rancière), ou, em outros termos, como espaço potencial de litígio (campos de força) e, a0 mesmo tempo, como constituição de formas específicas de comunidade que se inserem de modo peculiar na contemporaneidade. Trata-se, assim, de uma comunidade da não-identificação, uma comunidade inoperante, sem obra ou projeto de produção do sentido único, mas ainda como forma de exposição ao estar-em-comum e como abertura do significado (Nancy).

Palavras-chave: Revistas de poesia. Comunidade. Política da literatura.

\begin{abstract}
The object for reading and analysis in this study is a set of poetry magazines that has poets as the main editors and were or are still published in Brazil since the last decade of $20^{\text {th }}$ century. Collective practice and/or magazines of a single man? Are they singular and/or plural? Existences shut in themselves or participants in a shared chain of poetic experiences, objects and objectives? The purpose of this study is to analyze the hypothesis that the literary magazines may be considered as a condition of possibility for the politics of literature (Rancière), or, in other words, as a potential space for conflicts of interests and contentions (force fields) and, at the same time, as constitution of specific forms of community that are particularly inserted in the contemporaneity. Thus, it is about a non-identification community, an inoperative community, without a work or a project for production of the single sense, however still as form of exposition to the being-in-common and as opening of significance (Nancy).
\end{abstract}

Keywords: Poetry magazines. Community. Politics of literature.

Maria Lucia de Barros Camargo é professora titular de Teoria Literária na Universidade Federal de Santa Catarina, coordenadora do Núcleo de Estudos Literários \& Culturais e do Programa de Pós-Graduação em Literatura. 


\section{POR QUE AINDA LEMOS REVISTAS DE POESIA? APONTAMENTOS PARA O ESTUDO \\ DA POESIA BRASILEIRA EM SUAS REVISTAS ${ }^{*}$}

Maria Lucia de Barros Camargo

A pergunta exibida no título - um tanto retórica, porque talvez irrespondível - contém, de fato, uma afirmação, ou um pressuposto, modalizado pela temporalidade: revistas de poesia são lidas. São lidas ainda. A pergunta acerca da causa - por que? - toma como assente que revistas de poesia são lidas, ou melhor, continuam sendo lidas, isto é, já o foram no passado e continuam sendo-o no presente: ainda. Afirmar que revistas de poesia foram e continuam sendo lidas equivale também a dizer que revistas de poesia foram e continuam sendo produzidas e publicadas no Brasil.

Essa última afirmação pode ser constatada empiricamente com razoável facilidade, uma vez que as revistas, enquanto objeto palpável, coisa, matéria, existem e podem ser lidas e relidas, computadas, manuseadas, colecionadas, arquivadas. Desde a publicação das primeiras revistas simbolistas, na passagem do século XIX para o século XX, até este ano de 2013, podemos elencar um bom número de revistas dedicadas à poesia, mesmo que não exclusivamente. E esta série, vista ao longo do tempo, dá mostras de uma certa continuidade e, por que não, do interesse na produção dessas revistas, e, portanto, na produção e veiculação da própria poesia, apesar das alternâncias de ritmo, com períodos mais férteis entre outros de maior aridez ${ }^{1}$.

Lembremos também de um conjunto de "revistas de poetas", isto é, de revistas de poesia que circularam ou ainda circulam no Brasil, na forma impressa, a partir da última década do século $X X$, tendo poetas como seus editores. Prática coletiva e/ou revistas de um homem só? Singulares e/ou plurais? Existências encerradas em si mesmas e/ou partícipes de uma rede compartilhada de

\footnotetext{
* Uma versão prévia deste texto foi apresentada na $X$ Jornada Andina de Literatura Latinoamericana, realizada em Cali, Colômbia, em 2012.

${ }^{1}$ Esse conjunto, olhado a partir de uma pesquisa histórica, ainda precisa ser estudado.
} 
experiências, objetos e objetivos poéticos?

Talvez o ponto em comum entre essas revistas seja, de um lado, sua dimensão, e, de outro, em parte consequência do primeiro, sua efemeridade. Revistas de poesia podem ser chamadas de "pequenas revistas", para usar a tradução literal do termo consagrado na crítica norte-americana para designar as revistas literárias - little magazine. A expressão "pequenas revistas" foi usada no título da tradução brasileira do ensaio de Lionel Trilling sobre a Partisan Review, "A função da pequena revista" ${ }^{2}$. Trata-se de um artigo publicado originalmente em 1946, como introdução a uma antologia de textos da revista - The Partisan Reader - dedicado à comemoração dos 10 anos de existência da Partisan Review (1933-1944): uma "notável realização," diz Trilling, a simples existência, por 10 anos, de uma revista dedicada à literatura, e que teria conquistado nesse período um público de 6.000 leitores. Para Trilling, se as revistas literárias - as pequenas revistas, the little magazines, essas "aventuras privadas e precárias" - enfrentam dificuldades para manter os caminhos abertos e para manter vivos os novos talentos até que editores comerciais os publiquem, são exitosas em seu papel de resistência ao conformismo, ao populismo, às soluções facilitadoras.

O termo "pequenas revistas" é também o título utilizado na tradução do livreto de Reed Whittemore, originalmente intitulado Little magazines ${ }^{3}$, e publicado entre nós no mesmo ano que a tradução do livro de Lionel Trilling, com o propósito declarado de abordar, no "panfleto", os problemas cotidianos enfrentados pelos editores de pequenas revistas, dentre os quais se inclui o próprio Whittemore, que assim introduz seu assunto:

Pouca coisa é necessária para o início de uma pequena revista. Serão suficientes, como condições mínimas, uma máquina de escrever de segunda mão, certa quantidade de papel, e o acesso a algum mimeógrafo. O novo editor poderá, ele próprio, redigir e distribuir a revista a seus amigos. Pode-se, entretanto, dispender dinheiro em publicações dessa espécie. Na história das pequenas revistas, têm havido diversas aventuras mal sucedidas, realizadas em tonalidades várias,

\footnotetext{
2 In: TRILLING, Lionel. Literatura e sociedade. Trad. Rubem Rocha Filho. Rio de Janeiro: Lidador, 1965, p. 113-123. Na edição original, o livro se intitula The liberal imagination (Nova York: Viking, 1950). Na edição argentina, o título do artigo de Trilling é traduzido como "La función de la revista literaria" (In: La imaginación liberal. Trad. Enrique Pezzoni. Buenos Aires: Sudamericana, 1956).

${ }^{3}$ WHITTEMORE, Reed. Pequenas revistas. Trad. Anna Maria Martins. São Paulo: Livraria Martins Editora, 1965. Nos Estados Unidos o livreto foi publicado em 1963, pela University of Minnesota Pamphlets on American Writers, University of Minnesota Press.
} 
por fundações e viúvas ricas. A deficiência não é determinada pelo dinheiro dispendido, embora, de certa forma, o dinheiro tenha inevitavelmente pesado nisso, sobretudo na última década. ${ }^{4}$

Distinguindo as "pequenas revistas", que também recebem no panfleto a denominação "revistas sérias", daquelas destinadas à grande circulação e produzidas pela indústria editorial, Whittemore destaca o fato de estas revistas não constituírem, para seus editores, uma indústria, bem como o fato de, para se compreender esse gênero de publicação, o melhor é analisar as próprias revistas. Dentre as revistas comentadas, destaca-se Poetry, que mencionarei mais adiante.

Não há dúvida de que o termo "little magazine" - seja ele traduzido como pequena revista ou como revista literária - deve-se especialmente ao fato de tais revistas serem caracterizadas pelas tiragens reduzidas, pela periodicidade nem sempre mantida, e pela vida relativamente curta, o que se aplica às revistas literárias brasileiras, especialmente aquelas dedicadas à poesia ${ }^{5}$. De modo geral, também não são volumosas em número de páginas. É muito conhecida a frase atribuída a Olavo Bilac na qual o "príncipe dos poetas" se refere, não sem ironia e com certo humor, à efemeridade como uma doença, um mal que acomete as revistas de seu tempo. Está em uma de suas crônicas, relacionada a seu ingresso como cronista do jornal Gazeta de Notícias:

Entramos dous no mesmo dia, 24 de abril de 1890, trazidos pelas mãos de Ferreira Araújo. Aquele que entrou comigo já não vive, como já não vive aquele que nos pôs aqui dentro... Esse companheiro amado era Pardal Mallet: juntos fundáramos $A$ Rua, um jornal vermelho que morreu de "mal de sete... números", e logo depois viemos colaborar efetivamente na Gazeta. ${ }^{6}$

Um discurso repetido, talvez já um lugar-comum, atribui a morte precoce das revistas às dificuldades financeiras para sua manutenção, uma vez que não há assinaturas suficientes para sustentá-las, nem subvenção duradoura (seja pela fortuna pessoal dos envolvidos com a revista, seja por mecenato oficial),

\footnotetext{
${ }^{4}$ ibidem, p. 9.

${ }^{5}$ Não se incluem nesta série revistas institucionais, como é o caso de Poesia sempre, publicada com regularidade pela Biblioteca Nacional desde inícios dos anos 90 , em volumes alentados.

${ }^{6}$ DIMAS, Antônio (Org.). Vossa insolência. Crônicas. São Paulo: Companhia das Letras, 1996, p. 58. É interessante constatar que o jornal é o substituto da revista - de qualquer modo, Bilac continuava a publicar seus poemas em revistas ilustradas, como a Kosmos, que não faz parte da série de revistas a que nos referimos aqui.
} 
nem, muito menos, patrocínio empresarial (que interesse tem uma empresa em anunciar produtos num veículo de baixíssima circulação? Nem mesmo capital simbólico...). Em seminário sobre revistas literárias realizado em maio de 2012 na Casa de Rui Barbosa, no Rio de Janeiro, Jorge Viveiros de Castro relatava as dificuldades para a vendagem da Inimigo Rumor, talvez a mais prestigiosa revista de poesia das duas últimas décadas: publicar mais de 500 exemplares é (foi) encalhe certo.

Também não há, na cena cultural brasileira, nenhum periódico como, por exemplo, o Diário de Poesia, publicado em Buenos Aires desde o final da década de 80 do século passado, e vendido em bancas de jornal. No Brasil, as revistas de poesia são vendidas em algumas poucas livrarias. Mas o que se desconsidera é, talvez, a hipótese de que a efemeridade é própria dessa forma de veiculação da poesia, é mesmo sua condição de sobrevivência: seu fracasso, a morte das revistas, bem como seu ressurgimento como outra, a mesma, porém diferente, impede a constituição de um sentido coletivo unitário e autoritário.

É preciso lembrar, porém, que esse movimento não é o observado na revista Poetry - a magazine of verse, uma little magazine criada em 1912, em Chicago, nos Estados Unidos, por Harriet Monroe, e que completou em 2012 seu primeiro centenário! E continua sendo publicada. Se tal longevidade desmonta uma das principais características dessas revistas e, de um certo modo, poderia retirar a Poetry dos dias de hoje do rol das "pequenas revistas", essa mesma longevidade pode ser pensada como a exceção que confirma a regra. A importância de Poetry para a poesia de língua inglesa é incontestável e está intimamente ligada a seu correspondente estrangeiro e principal colaborador, Ezra Pound. Whittemore cita, por exemplo, uma declaração de Williams Carlos Williams: "Sem essa revista, a poesia, verdadeira 'avis rara', seria entre nós apenas uma reminiscência literária." 7

Muito voltada desde o início de sua circulação, em 1912, à formação de um público de poesia, até 1950 era possível ler a frase de Walt Whitman na sua contracapa: "Para haver grandes poetas é preciso que haja também um grande público" - mesmo que, diga-se, um público numericamente pequeno. De algum modo, é possível concordar com a ideia de que esse público de poesia se constitui a partir da existência das revistas de poesia, sejam elas efêmeras

${ }^{7}$ WHITTEMORE, Reed. Pequenas revistas, op. cit., p. 15. 
ou duradouras - como é o caso da própria Poetry em circulação até os dias atuais. Fato que ainda dá razão à recente afirmação de Marjorie Perloff sobre a formação dos leitores de poesia e que pode, também, ser aplicada ao Brasil: “Então, eu diria que o 'leitor' de jornais sabe muito pouco sobre poesia e crítica. No entanto, há leitores de poesia espalhados pelos EUA, formados, por assim dizer, pela cultura das pequenas revistas." ${ }^{8}$

Tais constatações nos conduzem de volta à pergunta inicial, de outro ângulo: sim, há no Brasil leitores para revistas de poesia, porém poucos. Neles se incluem os próprios poetas e fazedores de revistas. E mesmo considerando apenas o período dos últimos 20 anos, em que houve uma profusão de revistas de poesia em circulação, ainda assim, o que poderíamos chamar de uma comunidade de leitores de revistas de poesia, ou até de leitores de poesia, é bastante pequena quando pensamos na dimensão populacional do Brasil.

Uma comunidade de leitores de poesia; uma comunidade de poetas: o termo comunidade pressupõe a existência de elementos comuns, de laços, de cumplicidades; mas também, em outros termos, é preciso falar da comunidade dos que não têm comunidade (Bataille, Blanchot, Nancy), e de "políticas de amizade" que não pressupõem igualdade de pensamento (Derrida) em torno de um sentido.

Em outubro de 2001, sob o impacto da queda das torres gêmeas, Jean-Luc Nancy escreveu um prefácio para a tradução italiana de $A$ comunidade inconfessável, de Blanchot, livro que respondia a um artigo do mesmo Nancy, publicado em 1983 e que deu origem ao livro La communauté désœuvrée (1986). ${ }^{9}$ Neste prefácio, que é também um diálogo com Blanchot, Nancy traça um histórico dos textos filosóficos publicados na Europa a partir dos anos 80 sobre o tema da "comunidade". É interessante observar que o ponto de partida de Nancy - para tratar do tema no prefácio e em sua própria obra - foi uma proposta de Jean-Christophe Bailly, em 1983, de fazer um número especial da revista Aléa sobre "a comunidade", mote para o artigo acima citado. Não vou, neste espaço, apresentar ou comentar a questão filosófica de que trata Nancy acerca do tema. Mas é importante destacar aqui uma observação marginal de Nancy, uma nota de rodapé:

${ }^{8}$ PERLOFF, Marjorie. Contra as rotinas. In: Sibila. Revista semestral de poesia e cultura. São Paulo: Ateliê editorial, v. 1, n. 1, p. 14, out. 2001. Entrevista concedida a Régis Bonvicino.

9 O prefácio foi transformado em livro: La communauté affronté. Paris: Galilée, 2002; cito a partir da tradução para o espanhol, La comunidad enfrentada. Trad. J. M. Garrido. Buenos Aires: Ediciones La Cebra, 2007. 
Interrompeu [Bailly] esta publicação poucos anos depois, e buscaria então fundar outra revista, mais importante, com alguns outros, entre os quais me encontro [...]. Não houve editor com quem tratar esse projeto essencialmente complexo e diverso, porque nos negávamos a definir-nos por uma "linha" ou por um manifesto. A época das revistas fundadas por uma "ideologia" nos parecia encerrada (com Tel Quel e algumas outras). Quer dizer, também a época das revistas que formavam "comunidade", sem que a palavra, em todo caso, fosse empregada. Nosso grupo, muito variado, não formava comunidade. A história das revistas na França depois de 1950 certamente esclareceria vários aspectos do desaparecimento progressivo dos grupos, coletividades ou comunidades de "ideias", e, com isso, de uma mudança da representação de uma comunidade em geral. A revista fundada por Bataille, Critique, possuía um pressuposto completamente distinto, distanciado por princípio de toda identidade teórica. Não deixava, isto sim, de produzir nos anos 60 e 70 um efeito de "rede": era um lugar comum para aqueles que se distanciavam de toda comunidade. ${ }^{10}$

Grupo, coletividade, comunidade de ideias, rede: termos que aludem a diferentes formas de estar-juntos, e a diferentes organizações para as revistas. De fato, também neste espaço restrito em que se situam as revistas de poesia, pode-se dizer que a época das revistas que "formavam comunidade", isto é, que reuniam colaboradores e leitores em torno de manifestos de vanguarda, de chamamentos à participação na política - a poesia como arma — ou ainda em torno de palavras-de-ordem - está decretado o fim do verso - que convocavam à adesão (onipotência e onipresença, diz Nancy), a época dessas revistas não mais existe. Relembro aqui o "slogan" da capa do primeiro número da revista Sibila (2001) - o fim das vanguardas como elas eram para reescrevê-lo: lidamos com o fim das revistas como elas eram.

Se, por um lado, as revistas eram resultantes de um grupo, por outro, também podiam resultar na constituição de um grupo que pode ser pensado como formação (Raymond Williams) ou até como constituinte de comunidade, no sentido sociológico do termo, em que algo em comum identifica o pertencimento de seus membros e, até, o fechamento dessas comunidades sobre si mesmas, com o componente de violência e ressentimento que elas comportam ao se confrontarem. Procedimentos ou arranjos em torno de um sentido único, coletivo, e que se tornam visíveis não apenas nos enfrentamentos pelas polêmicas, mas também nos critérios de eleição e exclusão que pautam qualquer revista em qualquer dos modos.

\footnotetext{
${ }^{10}$ NANCY, Jean-Luc. La comunidad enfrentada, op. cit., p. 18. Tradução minha para o português.
} 
Ao comentar a "comunidade de Nancy" em posfácio à edição argentina de La comunidad enfrentada, Mónica Cragnolini destaca que a comunidade a que se referem Nancy e Blanchot (e toda a série que se deslancha a seguir), se diferencia da comunidade da sociologia por ser a "comunidade da não-identificação, da des-apropriação, da abertura à exposição ao outro." ${ }^{11}$ Se a comunidade sociológica se assenta na subjetividade moderna - "o homem como indivíduo (entidade fechada sobre si) em relações de reciprocidade, simetria e intercâmbio com outros indivíduos" ${ }^{12}$ - esta ideia não mais se sustenta (a queda das torres em Nova York o comprovam, diz Nancy), uma vez que "o outro", o Outro de si, faz implodir a ficção identitária. A comunidade, para Nancy, é, nas palavras de Cragnolini, "espaço de exposição, em que o 'ser-emcomum' ('estar-em-comum') é o inapropriável. [O] espaço é o 'estar fora' da comunidade." 13

Talvez possamos nos apropriar provisoriamente do inapropriável, para pensar que esse espaço do estar fora da comunidade, ou a comunidade inoperante, sem obra, sem projeto de produção do sentido único, em que é preciso resistir no limite, reconhecendo a estranheza do estranho, seja o espaço que permite as sobrevivências das revistas de poesia, não como elas eram. Talvez a poesia como resistência - o termo também é de Nancy - não a um governo ou Estado, ou ao modo de atuação dos governantes, dos partidos, dos detentores do poder, mas poesia como resistência tanto aos sentidos monolíticos quanto ao vazio, possa sustentar a sobrevivência das revistas sem grupos e sem comunidades de ideias. Mas ainda assim, comunidades. O que nos ajuda a entender a expressão - revista de um homem só - ouvida em algum lugar.

Se pensarmos nas recentes revistas feitas/dirigidas por poetas - em que não há nem grupos, nem comunidades identitárias claramente reconhecíveis (mesmo que nossa nostalgia queira sempre encontrá-las) - é o regime de afinidades eletivas que pode dar uma "cara" à revista, e esta é geralmente a da diversidade, mesmo que construída a partir de um poeta/editor solitário, cujas escolhas podem dar visibilidade a uma tensão subjacente: o desejo de constituir comunidades identitárias e a exposição das diferenças pela constituição de uma comunidade inoperante, um estar-junto nas páginas de um mesmo

\footnotetext{
${ }^{11}$ CRAGNOLINI, Mónica B. La comunidad de Nancy: entre la imposibilidad de representación y el silencio. In: NANCY, Jean-Luc. La comunidad enfrentada, op. cit., p. 62.

12 ibidem, p. 63.

${ }^{13}$ ibidem, p. 65.
} 
volume. É nessa tensão que as revistas se juntam, se separam, formam redes.

Em outros textos, tratando do mesmo conjunto de revistas, julguei ser possível divisar dois grandes blocos de revistas a partir de alguns aspectos. O primeiro deles considerava, além da publicação de poemas, a presença de textos críticos em umas e a total ausência deles noutras; de modo geral, as revistas que incluem crítica tendem a ser graficamente mais sisudas, sem ilustrações ou material visual; as outras, tendem a incluir entrevistas com os poetas publicados e muito material visual. Neste grupo, encontram-se revistas que parecem reivindicar seu caráter artístico através do desenho, da fotografia, de uma certa estetização da visualidade das páginas, tirando partido das novas possibilidades técnicas de edição, do que através da escritura poética.

Outro aspecto, um pouco mais complexo, diz respeito ao regime de escoIhas: mesmo que nenhuma dessas revistas adote dicções ou apostas estéticas fechadas (nada que lembre, por exemplo, o fechamento concretista), há certas nuances instigantes que passam pela reivindicação do passado - enquanto num grupo de revistas predominam os poetas já reconhecidos criticamente no escopo do modernismo e da experimentação de linguagem, mais afinados com o que se costuma identificar como rigor estético, outro grupo busca dar voz tanto a poetas pouco lembrados pela crítica (especialmente poetas que nos anos 60 não participavam dos grupos - comunidades? - predominantes, isto é, os que se inseriam na comunidade da experimentação de linguagem, concretista, e os que aderiram à arte popular revolucionária dos (PCs), quanto a outras opções poéticas, como a etnopoesia. Em comum, as revistas publicam novos poetas ao lado de poetas experimentados e até canônicos e reivindicam a defesa do valor, da qualidade literária, poética, mesmo que não se diga qual é, mesmo que se saiba da impossibilidade de dizê-lo.

Mas se estes agrupamentos poderiam levar à restauração da ideia de comunidades fechadas em si mesmas a partir de elementos de identificação entre seus membros, de pertencimento a uma seita, os contatos e as migrações de um grupo a outro nos aproxima da ideia de rede, talvez mesmo de rede rizomática, com agrupamentos, dispersões e reagrupamentos que afastam a ideia de fechamento ou de sentido único. Não configuram movimentos, comunidades, apenas diferenças, muitas vezes indistintas na massa de textos disseminada pelas páginas. Caberia, é verdade, nos ocuparmos mais detidamente do que ocorre com algumas revistas, poucas, que parecem não participar desta rede, não possuírem pontos de contato. Mas, de qualquer modo, existem 
como diferença.

Resistir, sobreviver, mesmo expostos à finitude. É isso que fazem as revistas e seus leitores, se concordamos com Nancy em que é a escritura a exposição ao estar-em-comum, a abertura do significado. E isso talvez nos ajude a entender porque ainda lemos revistas de poesia. Redes de revistas impressas, sobrevivências, arquivos: incompletos por definição, desorganizados, que requerem um trabalho de elaboração que os faça falar, que nos ajude a ler o modo como se dá, aí, a partilha do sensível, a política da literatura. Abrir esses arquivos anacrônicos do presente e colocá-los em confronto, no seu tempo e com seu passado, para discutir as "políticas do contemporâneo na literatura", é um dos desafios a que devemos nos propor. 